\title{
Accuracy of Blood Loss Measurement during Cesarean Delivery
}

\author{
Sahar V. Doctorvaladan, MD ${ }^{1}$ Andrea T. Jelks, MD ${ }^{1}$ \\ Mark I. Zakowski, MD ${ }^{3}$ David C. Lagrew, MD ${ }^{4}$ \\ ${ }^{1}$ Department of Obstetrics and Gynaecology, Santa Clara Valley \\ Medical Center, San Jose, California \\ 2 Gauss Surgical, Inc., Los Altos, California \\ 3 OB Anesthesiology, Cedars-Sinai Medical Center, Los Angeles, \\ California \\ ${ }^{4}$ Women's Health Institute, St. Joseph Hoag Health, Irvine, California
}

Eric W. Hsieh, BS ${ }^{2}$ Robert L. Thurer, MD²

Am J Perinatol Rep 2017;7:e93-e100.

\begin{abstract}
Objective This study aims to compare the accuracy of visual, quantitative gravimetric, and colorimetric methods used to determine blood loss during cesarean delivery procedures employing a hemoglobin extraction assay as the reference standard.

Study Design In 50 patients having cesarean deliveries blood loss determined by assays of hemoglobin content on surgical sponges and in suction canisters was compared with obstetricians' visual estimates, a quantitative gravimetric method, and the blood loss determined by a novel colorimetric system. Agreement between the reference assay and other measures was evaluated by the Bland-Altman method.

Results Compared with the blood loss measured by the reference assay ( $470 \pm 296$ $\mathrm{mL})$, the colorimetric system $(572 \pm 334 \mathrm{~mL}$ ) was more accurate than either visual estimation $(928 \pm 261 \mathrm{~mL})$ or gravimetric measurement $(822 \pm 489 \mathrm{~mL})$. The correlation between the assay method and the colorimetric system was more

Keywords

- cesarean delivery

- blood loss measurement

- postpartum hemorrhage

- quality improvement predictive (standardized coefficient $=0.951$, adjusted $R^{2}=0.902$ ) than either visual estimation (standardized coefficient $=0.700$, adjusted $R^{2}=00.479$ ) or the gravimetric determination (standardized coefficient $=0.564$, adjusted $R^{2}=0.304$ ).

Conclusion During cesarean delivery, measuring blood loss using colorimetric image analysis is superior to visual estimation and a gravimetric method. Implementation of colorimetric analysis may enhance the ability of management protocols to improve clinical outcomes.
\end{abstract}

Obstetrical hemorrhage is a potentially preventable cause of maternal morbidity and mortality, and its incidence is steadily increasing. ${ }^{1,2}$ Standardized approaches are being adopted to improve the care of these patients. ${ }^{3,4}$ Since poor outcomes can result from both delayed recognition and denial of the occurrence of significant bleeding ${ }^{3}$ and changes in maternal vital signs or laboratory parameters often provide late or misleading information, ${ }^{5-7}$ effective

received

January 11, 2017

accepted after revision

February 20, 2017
DOI http://dx.doi.org/

10.1055/s-0037-1601382. ISSN 2157-6998. measurement of ongoing blood loss is critical to early recognition.

Existing techniques for determining cumulative blood loss during cesarean procedures include visual estimation and a gravimetric method that involves weighing of soiled sponges and measurement of fluid in suction canisters. Since visual estimation frequently either over or underestimates the amount of bleeding 8,9 and requires continual retraining
Copyright $\odot 2017$ by Thieme Medical Publishers, Inc., 333 Seventh Avenue, New York, NY 10001, USA Tel: +1(212) 584-4662.
License terms




and constant vigilance during surgery, ${ }^{10}$ national organizations such as California Maternal Quality Care Collaborative (CMQCC), the Association of Women's Health, Obstetric and Neonatal Nurses (AWHONN), and the Council on Patient Safety in Women's Healthcare recommend weighing sponges to quantify blood loss. While this gravimetric method focuses providers on the importance of quantitatively assessing blood loss, it is cumbersome and has mixed data to validate its accuracy. ${ }^{11,12}$

The Triton system (Gauss Surgical, Inc., Los Altos, CA) is a novel U.S. Food and Drug Administration-cleared mobile application on a tablet computer (iPad) that uses the enabled tablet camera to capture images of surgical sponges. It performs colorimetric image correction and analysis and uses cloud-based machine-learning models to quantify hemoglobin $(\mathrm{Hgb})$ mass on surgical sponges in real time. The technology can also be used to measure the Hgb content of fluid collected in suction canisters during surgery and is accurate despite dilution with amniotic or other fluids. The performance of the device has been validated in bench-top and clinical settings. ${ }^{13-15}$

The objective of this study was to evaluate and compare the accuracy of visual estimation, quantitative gravimetric and colorimetric methods in determining cumulative blood loss during cesarean delivery procedures using a validated Hgb extraction assay method as the reference standard.

\section{Materials and Methods}

The protocol was approved by the Santa Clara Valley Medical Center Institutional Review Board (San Jose, CA) reference \#12-003; August 12, 2013. Canister and sponge samples from 50 consecutive patients having cesarean deliveries on weekdays between October and December 2015 were studied, and relevant patient and procedural information were collected and deidentified. Patients with known human immunodeficiency virus, hepatitis B virus or hepatitis C virus, were excluded. Standard methods of care were used throughout the procedures including fluid administration and the use and management of surgical sponges (RFDetect L1818-04P01C-1 18" ×18", RF Surgical Systems, Inc.) and suction canisters (Medi-Vac Guardian ${ }^{\mathrm{TM}}$ 65651-230 $3000 \mathrm{~mL}$, Cardinal Health, Inc.). Soiled laparotomy sponges were individually stored in sponge counting bags, and suction canisters were affixed with a label for recording amniotic and irrigation fluid volumes. Preprocedure and postoperative day $1 \mathrm{Hgb}$ values $(\mathrm{g} / \mathrm{dL})$ and all blood product transfusions given in the operating room were documented. Clinicians used only visually estimated blood loss (EBL) in making patient management decisions; they were blinded to results of the other assays.

For each patient, the cumulative blood loss was calculated from direct extraction assays of Hgb content on surgical sponges and in suction canisters. This result was compared with the attending obstetrician's visual estimate of blood loss, the measured blood loss using a quantitative gravimetric method and the blood loss determined by the colorimetric system.
Extraction assay: The Hgb recovery process draws from previously published methodology. ${ }^{16-20}$ Upon completion of each procedure, all soiled laparotomy sponges, and suction canisters were transferred to an on-site benchtop facility for $\mathrm{Hgb}$ extraction. Sponges were individually soaked in $400 \mathrm{~mL}$ of normal saline, compressed by hand for 60 seconds to a mean weight of $50 \mathrm{~g}$. This process was repeated four times. Hemoglobin concentration of the final extraction fluid was measured using the plasma/low spectrophotometer (HemoCue AB, Ängelholm, Sweden) and incorporated into the following formula to determine the total $\mathrm{Hgb}$ content of the sponge:

$H g b_{\text {sponge }}=\frac{\left(m_{\text {fluid }}+m_{\text {residual }}-m_{d r y}\right)}{\rho} \times \frac{[H g b]_{\text {fluid }}}{\%_{\text {yield }}}$

where $m_{\text {fluid }}$ represents the mass of the extraction fluid, $m_{\text {residual }}$ the mass of the fully extracted sponge, $m_{\text {dry }}$ the average dry weight of the sponge, $\rho$ the density of the extraction fluid approximated as $1.0 \mathrm{~g} / \mathrm{mL},[\mathrm{Hgb}]_{\text {fluid }}$ the $\mathrm{Hgb}$ concentration of extraction fluid, and \%yield the yield of the manual rinse extraction method. The yield was independently characterized by depositing banked blood on sponges in known quantities and performing the same mechanical extraction. A linear regression analysis revealed mean $\mathrm{mHgb}$ recovery rates of $89.5 \%$ (95\% confidence interval $[\mathrm{CI}]=86.8-92.1 \%)$ for individual sponges $(n=116)$.

Canister Hgb was determined by gently remixing the effluent, and transferring a $10 \mathrm{~mL}$ aliquot into a centrifuge tube. Two samples were drawn from the tube and measured using the plasma/low spectrophotometer for canisters ranging from 0 to $2.00 \mathrm{~g} / \mathrm{dL}$, or $\mathrm{Hb} 201+$ (HemoCue $A B$ ) for samples ranging from 2.0 to $25.6 \mathrm{~g} / \mathrm{dL}$, per instrument guidelines.

The canister fluid mass was measured using the digital scale, with an approximated density conversion of $1.0 \mathrm{~g} / \mathrm{mL}$ :

$$
H g b_{\text {canister }}=\frac{m_{\text {effluent }}}{\rho} \times[H g b]_{\text {effluent }}
$$

where $m_{\text {effluent }}$ represents the mass of the canister fluid, $\rho$ its density, and $[\mathrm{Hgb}]_{\text {effluent }}$ the Hgb concentration averaged over two samples.

The Hgb concentration in the canisters was separately assayed by using either a whole blood or low-concentration $\mathrm{Hgb}$ analyzer and converted to a canister blood volume first by converting the blood concentration $(\mathrm{g} / \mathrm{dL})$ of the canister to Hgb mass ( $\mathrm{g}$ ) by multiplying by the known total fluid volume in the canister, and then by dividing this canister $\mathrm{Hgb}$ mass $(\mathrm{g})$ by the patient's baseline Hgb concentration $(\mathrm{g} / \mathrm{dL})$. All blood loss measurements $(\mathrm{mL})$ were calculated by dividing Hgb mass readings by the patient's baseline (preoperative) $\mathrm{Hgb}$ value $(\mathrm{g} / \mathrm{dL})$. The blood loss in the canisters was then combined with the blood loss from the sponges to give a total assayed blood loss.

Visually EBL: At the conclusion of the procedure, the attending obstetrician visually estimated total blood loss based on examination of the surgical sponges and suction 
canisters, knowledge of the procedural specifics, and his or her estimate of the amount of amniotic fluid. The results were recorded independently, and the providers were blinded to the results of gravimetric, colorimetric or reference assay measurements to prevent confounding.

Quantitative blood loss ( $\left.Q B L_{G r a v}\right)$ : Quantitative gravimetric measurement methods were adopted from published guidelines. $^{3}$ At the time of the uterine incision, the surgical technician or nurse recorded the canister volume using the graduated markings. After aspirating all of the amniotic fluid, a second measurement was made, and the difference was recorded as the estimated amniotic fluid volume. At the conclusion of the procedure, the surgical technician recorded the total amount of irrigation fluid used. Immediately following the case, all sponges and suction canisters were individually weighed using a calibrated digital scale (A\&D Co. Ltd., Tokyo, Japan). Dry sponge weights were determined by weighing three packs of five sponges each before the study (mean $=21 \mathrm{~g}$, standard deviation $[\mathrm{SD}]=0.96 \mathrm{~g}$ ) and premeasured canister weights were subtracted. To determine the total $\mathrm{QBL}_{\mathrm{Grav}}$ estimate, all individual sponge and canister $\mathrm{QBL}_{\text {Grav }}$ measurements were tallied, and the amount of amniotic and irrigation fluid used was subtracted. The sponge fluid weight was expressed as a blood volume using a $1.0 \mathrm{~g} / \mathrm{mL}$ mean density conversion.

$$
\begin{gathered}
V_{\text {spongeQBL }}=\frac{m_{\text {wet }}-m_{\text {dry }}}{\rho} \\
V_{\text {canister } Q B L}=\frac{m_{\text {effluent }}}{\rho} \\
V_{\text {totalQBL }}=\Sigma V_{\text {spongeQBL }}+\Sigma V_{\text {canister } Q B L}-V_{\text {amniotic }} \\
-V_{\text {irrigation }}
\end{gathered}
$$

where $m_{\text {wet }}$ represents the mass of a soiled sponge, $V_{\text {spongeQBL }}$ the gravimetric blood volume estimate on a sponge, $V_{\text {canisterQBL }}$ the gravimetric blood volume estimate in a canister, $V_{\text {amniotic }}$ the amniotic fluid volume estimate, and $V_{\text {irrigation }}$ the measured amount of irrigation fluid.

Colorimetric: Following the case, all surgical sponges were collected and scanned using the Triton sponge application (Version 2.0.9). This resulted in a measured amount of Hgb loss per sponge $(\mathrm{g})$ that was converted to a volumetric measure based on the patient's preprocedure Hgb value (g/dL). Also, the surgical canisters used to collect blood and fluid from the operative field were scanned using the Triton canister application (Version 1.0.37-61), and the concentration of Hgb in the canisters was determined. This concentration was multiplied by the volume of fluid in the canister, and the resultant total $\mathrm{Hgb}$ in the canister was converted to a volumetric measurement of blood loss based on the patient's preprocedure Hgb value.

\section{Statistical Analysis}

Variables are expressed in mean $\pm \mathrm{SD}$, median/interquartile range or count (\%) as appropriate. Kolmogorov-Smirnov test was used to evaluate whether the continuous variables followed a normal distribution. For parameter estimates, 95\% CIs are provided. Additional analyses were performed using $t$-test, Mann-Whitney $U$ test, Wilcoxon signed ranks test, and Pearson or Spearman correlations as appropriate. Volumetric blood loss measurement using the extraction assay and the other measurements $\left(\mathrm{EBL}, \mathrm{QBL}_{\mathrm{Grav}}\right.$, and colorimetric) were compared using a two-sided paired $t$-test.

Agreement between the extraction assay and other measurements (EBL, $\mathrm{QBL}_{\mathrm{Grav}}$, and colorimetric) was evaluated using the Bland-Altman method, an analysis framework that has been widely established as the standard for the comparison of the clinical differences between two different measurement methods. ${ }^{21}$ The Bland-Altman bias (mean the difference between the two measures) and upper and lower limits of agreement (mean $\pm 1.96 \times \mathrm{SD}$ ) with their respective 95\% CIs were computed.

As in previous studies, an acceptance criterion of $\pm 30 \mathrm{~g}$ of Hgb per case was set a priori as the clinically acceptable maximum bias. ${ }^{22}$ This difference represents approximately $5 \%$ of the total blood volume of an average adult ( $\mathrm{Hgb}$ content of $\sim 250 \mathrm{~mL}$ [approximately $1 / 2$ unit] of whole blood). Prior studies with Triton ${ }^{13-15}$ indicated that the SD of the Hgb mass bias was relatively low ( $\sim 10$ g or less) compared with the acceptance criterion ( $\pm 30 \mathrm{~g}$ ), and therefore a sample size of 50 cases was deemed adequate as it provided a $95 \% \mathrm{CI}$ of \pm $0.5 \times \mathrm{SD}$ (approximately $\pm 5 \mathrm{~g}$ ) around the limits of agreement. ${ }^{23}$ This sample size would allow $90 \%$ certainty that the limits of a two-sided $95 \% \mathrm{CI}$ will exclude a bias of $7.25 \times \mathrm{SD}$ if there were truly no difference between the two measurement methods. Statistical analyses were performed using SPSS (version 13.0, SPSS, Inc.).

\section{Results}

Data were successfully collected from all 50 cases. Mean preand postoperative Hgb levels were $12.2 \pm 1.0$ and $10.8 \pm 1.2$ $\mathrm{g} / \mathrm{dL}$, respectively ( $p<0.001$ for the paired comparison of pre- and postoperative Hgb levels). One patient received a single unit packed red cell transfusion intraoperatively.

The mean patient age was 31.9 years (range $=19-44$ years). Overall, 44 mothers were multiparas. All babies were singleton. A total of 41 procedures were elective. The indications for delivery included 32 elective repeat deliveries, eight breech presentations, and the remainder for a variety of other reasons. Six mothers labored before delivery although all had intact membranes. Gestational ages ranged from 31 to 41 weeks and one day with 38 being 39 weeks or greater.

The mean amniotic fluid volume as recorded intraoperatively by marking the suction canister for volumetric assessment was $632 \pm 507 \mathrm{~mL}$ (median $=500 \mathrm{~mL}$, - Fig. 1) and the mean measured irrigation fluid volume was $759 \pm 437 \mathrm{~mL}$. As measured by the assay the mean amount of blood contained in a laparotomy sponge was $24.5 \pm 20.3 \mathrm{~mL}$, and the average canister contained $236 \pm 137 \mathrm{~mL}$ of blood (-Fig. 2). An average of 15 sponges and one canister were used for each procedure. The mean blood loss per procedure as measured by the assay was $470 \pm 296 \mathrm{~mL}$ (range $=113-1,614 \mathrm{~mL}$ ). In four cases, the total blood loss exceeded 1,000 $\mathrm{mL}$ (-Fig. 3 ). 


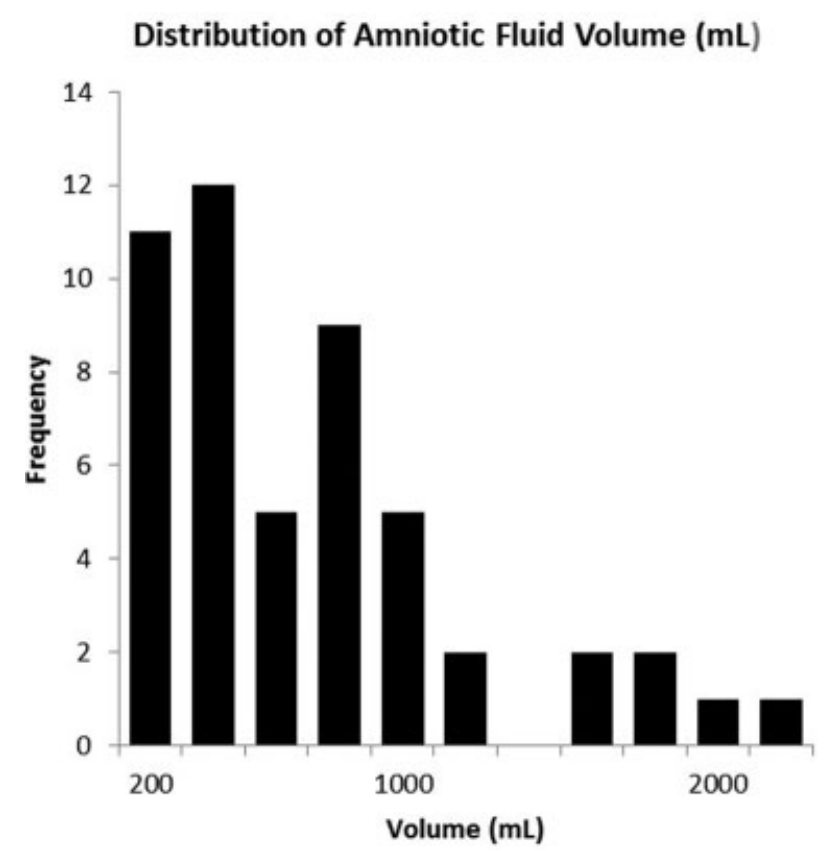

Fig. 1 Distribution of amniotic fluid volume recorded by marking the suction canister for volumetric assessment.

The visual, gravimetric, and colorimetric methods of estimating blood loss all demonstrated positive bias (mean difference between two methods of measurement) about the extraction assay, at 458, 352, and $102 \mathrm{~mL}$, respectively. Both the visual and gravimetric methods systematically overestimated blood loss more than the clinical tolerance of $1 / 2$ a unit of whole blood, or $250 \mathrm{~mL}$ (-Table 1).

The gravimetric method was evaluated to understand the source of its inaccuracy better. Of the 757 sponges measured, $\mathrm{QBL}_{\mathrm{Grav}}$ exceeded the blood content determined by the assay method in all but 8 . The $\mathrm{QBL}_{\mathrm{Grav}}$ measurements exhibited poor correlation $\left(r^{2}=0.2682\right)$ with the assay and system-

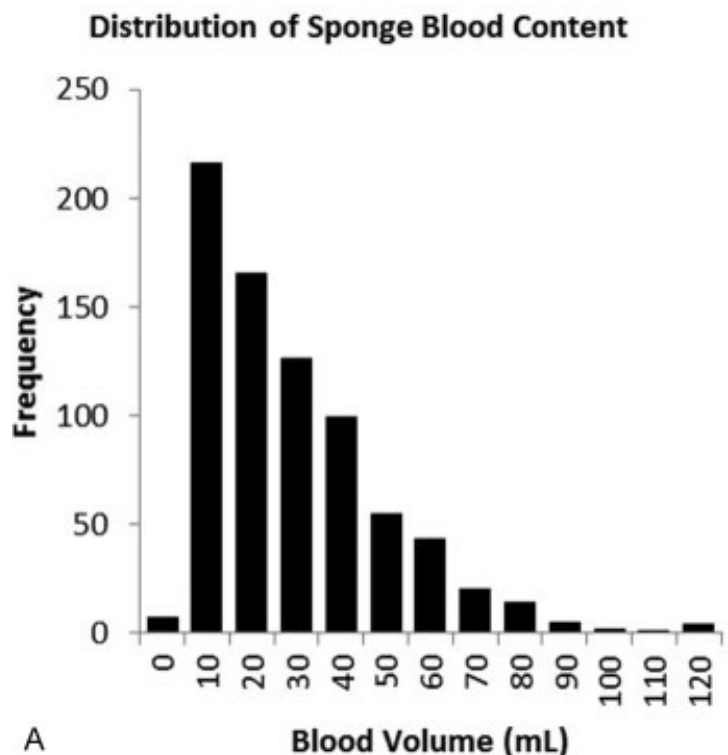

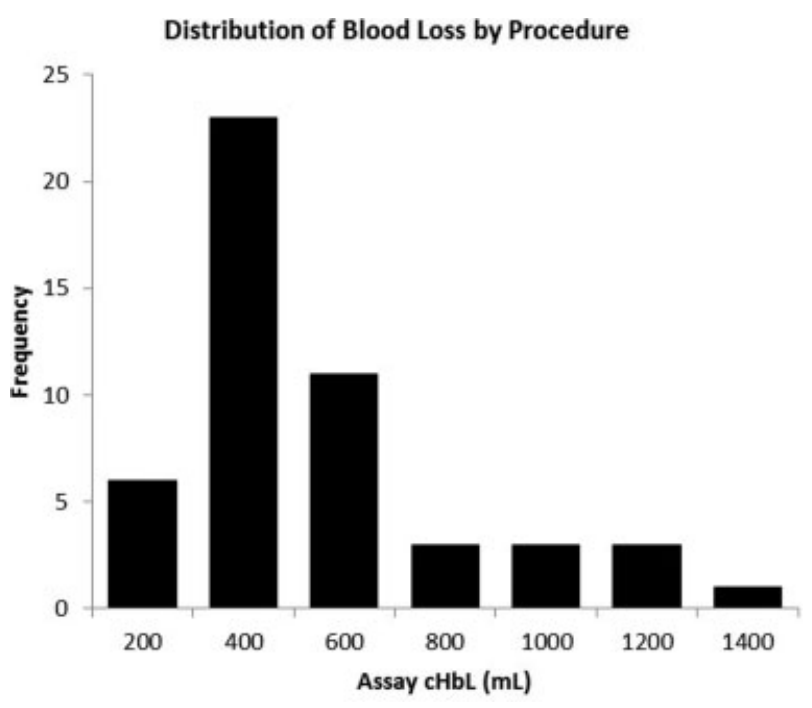

Fig. 3 Distribution of blood loss as determined by the assay method.

atically overestimated sponge blood content ( - Fig. 4) most likely due to the addition of absorbed amniotic and irrigation fluid to the blood collected on the sponges. This inaccuracy persisted despite the corrections for amniotic and irrigation fluid that were made to the total blood loss measures.

The relationship between blood losses measured by the various methods versus the extraction assay method is described in - Table 2 and illustrated by scatter plots in - Fig. $\mathbf{5}$. Assessment of agreement between the various measurements and the extraction assay method according to Bland-Altman method is provided in - Table 3 and - Figs. 6-8.

\section{Comment}

This study demonstrates that when using an extraction assay method as a reference standard, cumulative blood loss is

\section{Distribution of Canister Blood Content}

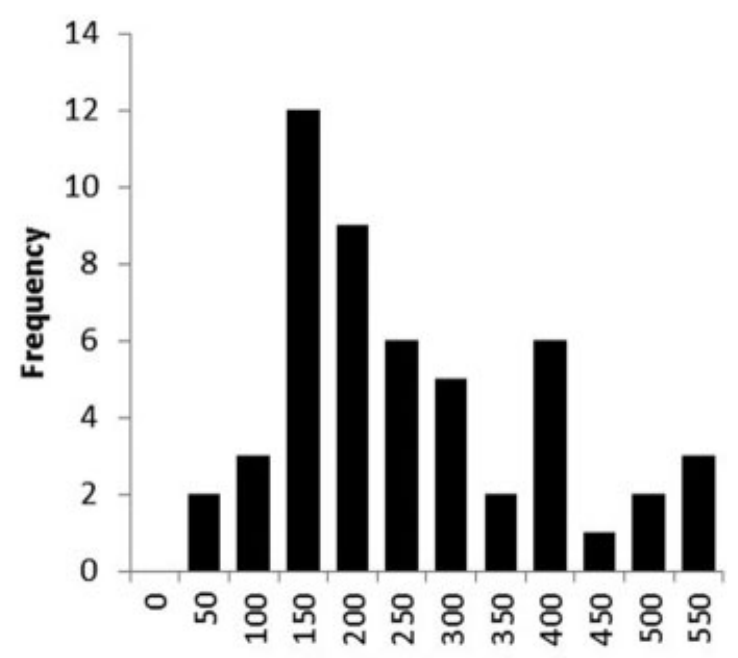

B Blood Volume $(\mathrm{mL})$

Fig. 2 (A) Distribution of sponge blood content as measured by the assay method. (B) Distribution of canister blood content as measured by the assay method. 
Table 1 Blood loss determinations

\begin{tabular}{|c|c|c|c|c|c|}
\hline & Method & Extraction Assay & Visual EBL & $\begin{array}{l}\mathrm{QBL}_{\mathrm{Grav}} \\
\text { (adjusted) }^{\mathrm{a}}\end{array}$ & Colorimetric \\
\hline \multirow[t]{4}{*}{ Sponge (mL) } & Mean \pm SD & $280 \pm 222$ & & $759 \pm 317$ & $332 \pm 255$ \\
\hline & Median (IQR) & $203(138)$ & & $695(426)$ & $251(181)$ \\
\hline & Bias $(95 \% \mathrm{Cl})$ & & & $480(428-531)$ & $52(32-71)$ \\
\hline & $p$ Value & & & $<0.001$ & $<0.001$ \\
\hline \multirow[t]{4}{*}{ Canister $(\mathrm{mL})$} & Mean \pm SD & $190 \pm 133$ & & $63 \pm 335$ & $240 \pm 137$ \\
\hline & Median (IQR) & $142(173)$ & & $-13(285)$ & $199(202)$ \\
\hline & Bias $(95 \% \mathrm{Cl})$ & & & $\begin{array}{l}-127 \\
(-228 \text { to }-26)\end{array}$ & $50(26-74)$ \\
\hline & $p$ Value & & & 0.014 & $<0.001$ \\
\hline \multirow{4}{*}{$\begin{array}{l}\text { Total blood loss } \\
\text { per procedure } \\
(\mathrm{mL})\end{array}$} & Mean \pm SD & $470 \pm 296$ & $928 \pm 261$ & $822 \pm 489$ & $572 \pm 334$ \\
\hline & Median (IQR) & $384(296)$ & $800(200)$ & $651(475)$ & $481(332)$ \\
\hline & Bias $(95 \% \mathrm{Cl})$ & & $458(396-520)$ & $352(237-467)$ & $102(72-132)$ \\
\hline & $p$ Value & & $<0.001$ & $<0.001$ & $<0.001$ \\
\hline
\end{tabular}

Abbreviations: $\mathrm{Cl}$, confidence interval; EBL, estimated blood loss; IQR, interquartile range; $\mathrm{QBL}_{\mathrm{Grav}}$, quantitative blood loss; SD, standard deviation.

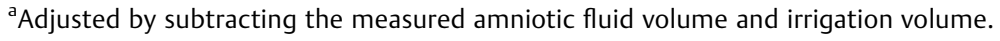

Note: $p$ Values reflect the statistical significance level of paired $t$-tests comparing each method with the extraction assay (reference standard).

more accurately assessed by the colorimetric method than by either visual estimation or the widely recommended quantitative gravimetric method. Visual estimation demonstrated a slightly better correlation to the assay than gravimetric estimation because, despite adjustments, the quantitative gravimetric method tended to overestimate blood loss consistently. This was presumably due to the effects of amniotic fluid and irrigants that inevitably mix with the blood collected on surgical sponges and within suction canisters confounding the results of weighing the sponges and measuring the volume in the canisters.

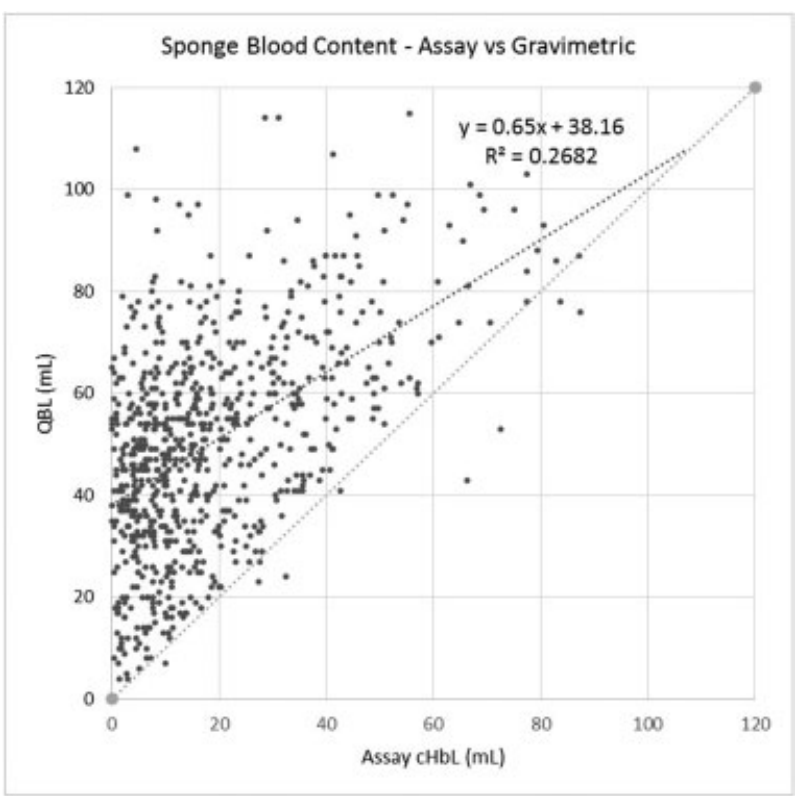

Fig. 4 Scatter plot of the blood content of each sponge comparing the assay and gravimetric methods.
The regression curve for visual estimation demonstrates a slope well below 1.0 suggesting that the providers' estimates of the amount of blood loss were virtually unrelated to the reference values (-Fig. 5A). In fact, if a few of the high estimates were removed the slope would have approached zero. Clinicians never estimated a blood loss of less than $500 \mathrm{~mL}$, and yet the reference data demonstrates that $66 \%$ of patients had such values. These data confirm that surgeons and other medical personnel are inaccurate in visually estimating blood loss. ${ }^{9}$

Historical data supporting the quantitative gravimetric method of measuring blood loss is mixed. For example, Lilley et $\mathrm{al}^{12}$ concluded that in a mixed group of vaginal and cesarean deliveries gravimetric assessment of blood loss during postpartum hemorrhage ( $\mathrm{PPH}$ ) was effective, while Johar et al, ${ }^{11}$ determined that in surgical procedures the technique was frequently inaccurate due to issues such as recording bias, amniotic fluid/saline corruption, and human error. Data from this study illustrate the persistent challenges posed by this methodology in cesarean deliveries where blood and nonsanguineous fluids frequently mix. Specifically, the quantitative gravimetric technique showed a lower correlation with actual blood loss than the colorimetric method as evidenced by the lower R-value. This variation includes several cases where there was a significant deviation, both above and below the actual blood loss. In $34 \%$ of the cases the quantitative gravimetric method overestimated the blood loss by greater than $500 \mathrm{~mL}$ when compared with the reference standard (mean $=761 \pm 370 \mathrm{~mL}$ for those cases) and in two cases the quantitative gravimetric method underestimated the blood loss by more than $500 \mathrm{~mL}$. However, unlike visual estimation, gravimetric methods did effectively quantify blood losses of less than $500 \mathrm{~mL}$ in many patients. The cases where the gravimetric estimate 
e98 The accuracy of Blood Loss Measurement during Cesarean Delivery Doctorvaladan et al.

Table 2 Linear correlation of blood loss measurements versus extraction assay (reference standard)

\begin{tabular}{|l|l|l|l|l|}
\hline Method & Correlation coefficient $(95 \% \mathrm{CI})$ & Standardized coefficient & $p$ Value & ${\text { Adjusted } \mathbf{R}^{2}}$ \\
\hline Visual EBL & $0.700(0.523-0.819)$ & 0.700 & $<0.001$ & 0.479 \\
\hline QBL $_{\text {Grav }}$ (adjusted) & $0.564(0.339-0.728)$ & 0.564 & $<0.001$ & 0.304 \\
\hline Colorimetric & $0.951(0.915-0.972)$ & 0.951 & $<0.001$ & 0.902 \\
\hline
\end{tabular}

Abbreviations: $\mathrm{Cl}$, confidence interval; EBL, estimated blood loss; QBLGrav, quantitative blood loss.
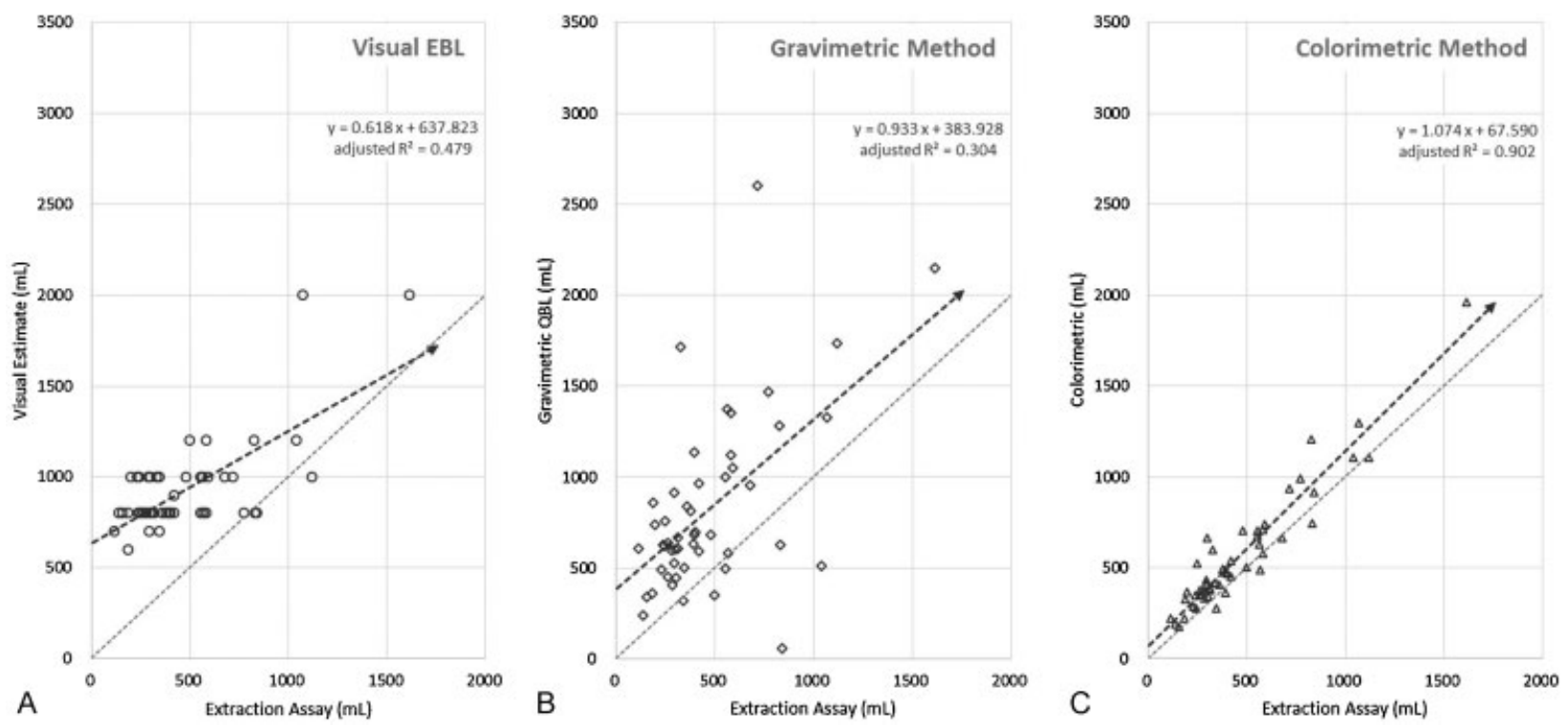

Fig. 5 Scatter plots of blood loss measured by (A) visual estimation, (B) gravimetric method, and (C) colorimetric method compared with the assay method. A line of unity representing perfect correlation is shown for comparison.

of blood loss was greater than the blood loss calculated from the Hgb loss determined by the extraction assay method can be plausibly explained by visual underestimation of the amount of irrigation and amniotic fluid in the canister, lower preoperative $\mathrm{Hgb}$ concentration (since the weight of additional plasma is included) or significant amounts of irrigation and/or amniotic fluid on the sponges. Underestimation by the quantitative gravimetric method likely resulted from the reverse of these conditions.

Accurate blood loss estimation is clinically valuable and may substantially alter the timing of interventions to control hemorrhage. Overestimation during cesarean delivery may lead patients, particularly those who have minimal postpartum blood loss following the procedure, to have unnecessary laboratory evaluation and exposure to unneeded medications and/or transfusions. Conversely, underestimation may lead to a delay in evaluation and treatment, particularly if further blood loss occurs postpartum. This risk may be exacerbated by the fact that patients with presumed low blood loss may be placed in care environments with the lower nurse to patient ratios and less intensive monitoring. Furthermore, patients with

Table 3 Assessment of agreement between methods of measuring blood loss and the extraction assay (reference standard)

\begin{tabular}{|l|l|l|l|}
\hline & Visual EBL $(\mathrm{mL})$ & $\mathrm{QBL}_{\text {Grav }}$ (adjusted) $(\mathrm{mL})$ & Colorimetric $(\mathrm{mL})$ \\
\hline Bias $(95 \% \mathrm{Cl})(\mathrm{mL})$ & 458 & 352 & 102 \\
\hline SD (error) $(\mathrm{mL})$ & 218 & 405 & 106 \\
\hline Upper limit of agreement $(95 \% \mathrm{Cl})(\mathrm{mL})$ & 886 & 1,145 & 309 \\
\hline Lower limit of agreement $(95 \% \mathrm{Cl})(\mathrm{mL})$ & 31 & -441 & -105 \\
\hline RMSE $(\mathrm{mL})$ & 507 & 533 & 146 \\
\hline $\mathrm{Cl}($ bias $)$ & 62 & 115 & 30 \\
\hline $\mathrm{Cl}\left(\right.$ LOAs)-calculated as $\left[1.96 \times S D \times \sqrt{\frac{3}{n}}\right]$ & 105 & 194 & 51 \\
\hline
\end{tabular}

Abbreviations: Cl, confidence interval; EBL, estimated blood loss; LOA, limits of agreement; $Q_{B} L_{G r a v}$, quantitative blood loss; RMSE, root mean square error; SD, standard deviation. 


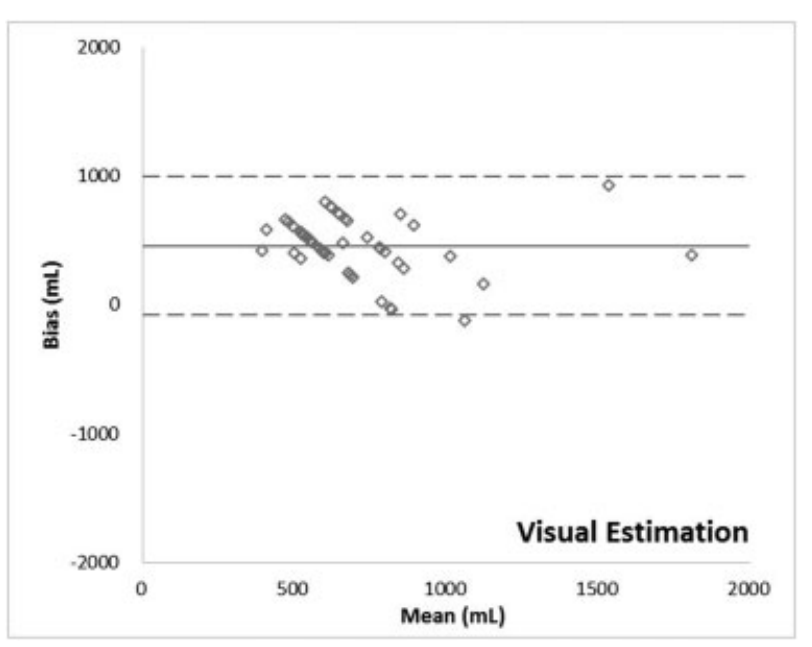

Fig. 6 Bland-Altman plot: Visual method.

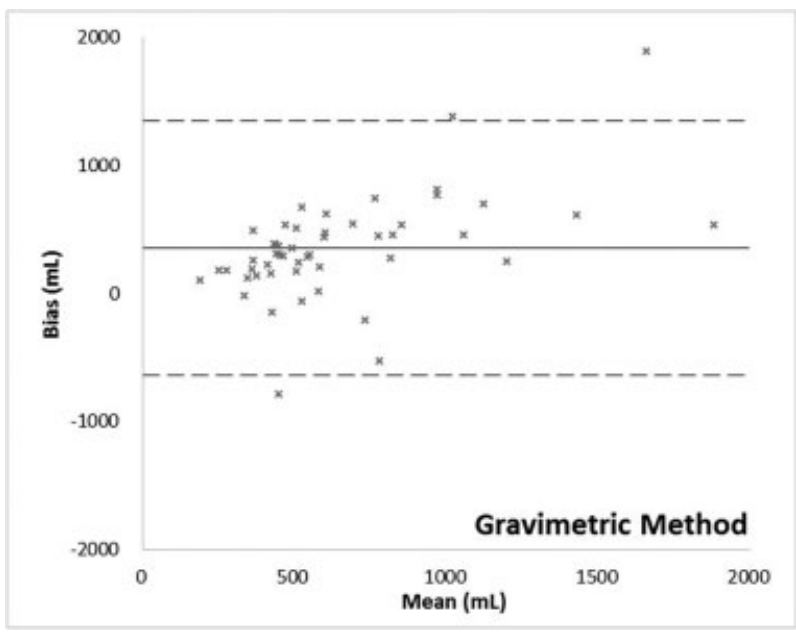

Fig. 7 Bland-Altman plot: Gravimetric method.

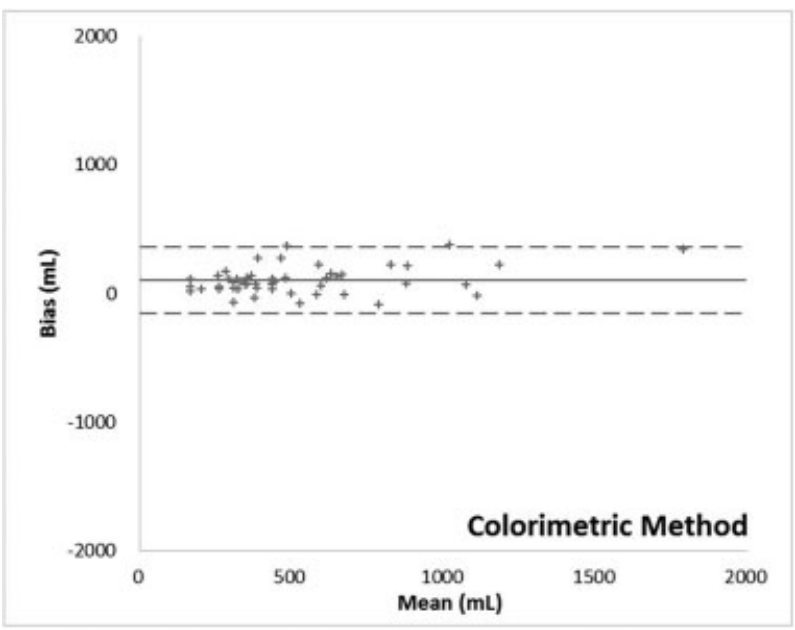

Fig. 8 Bland-Altman plot: Colorimetric method.

underestimated blood loss may not receive appropriate blood, or blood component therapy is potentially leading to excessive hemorrhage from dilutional anemia and/or coagulopathy.
A limitation of this study is that it investigated a patient population having surgical blood losses mostly within the normal range. The population studied did not have a substantial number of patients with excessive blood loss, and therefore comparisons between the various methods could not be made for that situation. Nonetheless, the colorimetric method is likely to be accurate in patients experiencing massive hemorrhage since the study validates the comparative accuracy of colorimetry in measuring blood loss on individual sponges and in each canister. In cases with increased hemorrhage, one would expect that there would simply be more sponges and larger volumes in the canisters. In contrast, both visual estimation and the quantitative gravimetric method would be prone to greater variation with increased blood loss. A strength of this study is that a rigorous and detailed evaluation of all three methods was conducted and compared the results to a validated reference standard. Although all sponge/canister image capture and analysis in this study was done at the conclusion of surgery, the use of this tool has previously been effectively implemented "real-time" during surgical procedures, thus providing continuous and ongoing monitoring of blood loss. ${ }^{15}$

The blood losses measured in this study were typically less than that commonly estimated for cesarean delivery. This may be due to the failure of the extraction assay, colorimetric and gravimetric methods to account for blood loss on surgical drapes. Alternatively, the data could be interpreted as demonstrating that those traditional estimates are often incorrect. Further studies are needed to determine whether data using the colorimetric method is sufficiently accurate to predict postoperative $\mathrm{Hgb}$ levels and guide therapy.

This study demonstrates that both visual and quantitative gravimetric methods of measuring blood loss during cesarean deliveries are unreliable and colorimetric image analysis using a computer-based algorithmic system provides more accurate results. Accurate, real-time measurement of blood loss has the potential to facilitate proper implementation of obstetric hemorrhage protocols to improve patient care. Further study of these methods and workflows, particularly in patients with larger amounts of perioperative bleeding, is warranted.

\section{Conflict of Interest}

Mr. Hsieh and Dr. Thurer are employees of Gauss Surgical, Inc. The remaining authors have no conflicts to report.

\section{Acknowledgments}

Financial Support: Gauss Surgical, Inc. provided statistical support services and the colorimetric device used in the study. Gauss personnel also participated in study design, data collection, and analysis, and article preparation.

The authors would like to recognize and thank Keng-Tsai Lin, BS, Xuan Dang, BS, and John-Allen Smith, BA, Research Associates, Gauss Surgical, Inc. and Mazyar Javidroozi, MD, $\mathrm{PhD}$, Director, Clinical Research, Department of 
Anesthesiology, Englewood Medical Center, Englewood, NJ for their contributions to this study.

\section{References}

1 Callaghan WM, Kuklina EV, Berg CJ. Trends in postpartum hemorrhage: United States, 1994-2006. Am J Obstet Gynecol 2010; 202(04):353.e1-353.e6

2 Berg CJ, Harper MA, Atkinson SM, et al. Preventability of pregnancy-related deaths: results of a state-wide review. Obstet Gynecol 2005;106(06):1228-1234

3 Lyndon A, Lagrew D, Shields L, Main E, Cape V. Improving Health Care Response to Obstetric Hemorrhage. (California Maternal Quality Care Collaborative Toolkit to Transform Maternity Care) Developed under contract \#11-10006 with the California Department of Public Health; Maternal, Child and Adolescent Health Division; Published by the California Maternal Quality Care Collaborative, 3/17/15. Available at: http://health.utah.gov/ uwnqc/documents/CaliforniaToolkittoTransformMaternityCare. pdf. Accessed August 1, 2016

4 Main EK, Goffman D, Scavone BM, et al; National Partnership for Maternal Safety; Council for Patient Safety in Women's Health Care. National Partnership for Maternal Safety: consensus bundle on obstetric hemorrhage. Anesth Analg 2015;121(01):142-148

5 Brasel KJ, Guse C, Gentilello LM, Nirula R. Heart rate: is it truly a vital sign? J Trauma 2007;62(04):812-817

6 Convertino VA, Moulton SL, Grudic GZ, et al. Use of advanced machine-learning techniques for noninvasive monitoring of hemorrhage. J Trauma 2011;71(1, Suppl):S25-S32

7 Orlinsky M, Shoemaker W, Reis ED, Kerstein MD. Current controversies in shock and resuscitation. Surg Clin North Am 2001; 81(06):1217-1262, xi-xii

8 Bose P, Regan F, Paterson-Brown S. Improving the accuracy of estimated blood loss at obstetric haemorrhage using clinical reconstructions. BJOG 2006;113(08):919-924

9 Schorn MN. Measurement of blood loss: review of the literature. J Midwifery Womens Health 2010;55(01):20-27

10 Toledo P, Eosakul ST, Goetz K, Wong CA, Grobman WA. Decay in blood loss estimation skills after web-based didactic training. Simul Healthc 2012;7(01):18-21

11 Johar RS, Smith RP. Assessing gravimetric estimation of intraoperative blood loss. J Gynecol Surg 1993;9(03):151-154
12 Lilley G, Burkett-St-Laurent D, Precious E, et al. Measurement of blood loss during postpartum haemorrhage. Int J Obstet Anesth 2015;24(01):8-14

13 Holmes AA, Konig G, Ting V, et al. Clinical evaluation of a novel system for monitoring surgical hemoglobin loss. Anesth Analg 2014;119(03):588-594

14 Konig G, Holmes AA, Garcia R, et al. In vitro evaluation of a novel system for monitoring surgical hemoglobin loss. Anesth Analg 2014;119(03):595-600

15 Sharareh B, Woolwine S, Satish S, Abraham P, Schwarzkopf R. Real time intraoperative monitoring of blood loss with a novel tablet application. Open Orthop J 2015;9:422-426

16 Hill SE, Broomer B, Stover J, White W. Accuracy of estimated blood loss in spine surgery. In: Proceedings of the American Society of Anesthesiologists (ASA) 2011 Annual Meeting. ; October 15-19, 2011 Chicago, IL. Abstract A054

17 Hill SE, Broomer B, Stover J, White W, Richardson W. Bipolar tissue sealant device decreases hemoglobin loss in multilevel spine surgery. Transfusion 2012;52(12):2594-2599

18 Newton J, Barnard G, Collins W. A rapid method for measuring menstrual blood loss using automated extraction. Contraception 1977; 16:269-282

19 Magnay JL, Schönicke G, Nevatte TM, O’Brien S, Junge W. Validation of a rapid alkaline hematin technique to measure menstrual blood loss on feminine towels containing superabsorbent polymers. Fertil Steril 2011;96(02):394-398

20 van Eijkeren MA, Scholten PC, Christiaens GC, Alsbach GP, Haspels AA. The alkaline hematin method for measuring menstrual blood loss-a modification and its clinical use in menorrhagia. Eur J Obstet Gynecol Reprod Biol 198622(5-6): 345-351

21 Bland JM, Altman DG. Statistical methods for assessing agreement between two methods of clinical measurement. Lancet 1986;1 (8476):307-310

22 Guinn NR, Broomer BW, White W, Richardson W, Hill SE. Comparison of visually estimated blood loss with direct hemoglobin measurement in multilevel spine surgery. Transfusion 2013;53(11):2790-2794

23 Bland JM, Altman DG. How can I decide the sample size for a study of agreement between two methods of measurement? Updated: January 12, 2004. Available at: http://www-users.york.ac.uk/ $\sim$ mb55/meas/sizemeth.htm. Accessed September 23, 2016 